\title{
SOME VIRTUES OF EVIDENTIALISM
}

\author{
Richard Feldman*
}

Earl Conee*

SÍNTESE - O evidencialismo é, primordialmente, uma tese sobre a justificação epistêmica e, secundariamente, uma tese sobre o conhecimento. Sustenta que a justificação epistêmica é superveniente da evidência. As versões do evidencialismo diferem quanto ao que conta como evidência, quanto ao que seja possuir algo como evidência e quanto ao que um dado corpo de evidência apóia. A tese secundária é a de que o apoio evidencial é necessário ao conhecimento. O evidencialismo ajuda a formular as questões epistemológicas de uma forma que é ótima para que se perceba o núcleo dos problemas. Oferece soluções, sem mascarar as dificuldades. Nós fornecemos ilustração disso através da consideração dos problemas da justificação a priori e do ceticismo. $\mathrm{O}$ evidencialismo também oferece a base para que se compreenda uma grande variedade de fatos e conceitos epistemológicos. Nós fornecemos ilustração disso, mostrando que o evidencialismo pode explicar como a justificação pode ser anulada, como as atitudes distintas da crença podem ser objeto de avaliação e como a própria prática da filosofia é epistemicamente valiosa.

PALAVRAS-CHAVE - Evidencialismo. Evidência. Justificação. Conhecimento. A priori. Ceticismo.
ABSTRACT - Evidentialism is primarily a thesis about epistemic justification and secondarily a thesis about knowledge. It holds that epistemic justification supervenes on evidence. Versions of evidentialism differ about what counts as evidence, what it is to have something as evidence, and what a particular body of evidence supports. The secondary thesis is that evidential support is necessary for knowledge. Evidentialism helps to frame epistemological issues in a way that is optimal for seeing the heart of the problems. It offers solutions without disguising the difficulties. We illustrate this by considering the problems of a priori justification and skepticism. Evidentialism also provides the basis for understanding a variety of epistemological facts and concepts. We illustrate this by showing that evidentialism can explain how justification can be defeated, how attitudes other than belief can be the object of evaluation, and how the practice of philosophy itself is epistemically valuable.

KEY WORDS - Evidentialism. Evidence. Justification. Knowledge. A priori. Skepticism.

Evidentialism is primarily a thesis about the nature of epistemic justification and secondarily a thesis about the nature of knowledge. The primary thesis holds that epistemic justification is a function of evidence: A person's doxastic attitudes are epistemically justified if and only if they fit the evidence that the person has. Many more precise versions of this evidentialist thesis can be formulated. They differ about exactly what counts as evidence, what it is for a person to have some-

* Department of Philosophy - University of Rochester.

\begin{tabular}{|l|l|l|l|l|l|}
\hline VERITAS & Porto Alegre & v. 50 & n. 4 & Dezembro 2005 & p. 95-108 \\
\hline
\end{tabular}


thing as evidence, and what propositions or attitudes a particular body of evidence supports. The evidentialist thesis about knowledge is that justification, understood in evidentialist terms, is necessary for knowledge. Versions of the theory can differ about what degree of support is required for knowledge and what other conditions are required for knowledge.

In this paper we highlight some virtues of the evidentialist perspective. ${ }^{1}$ They fall into a few rough and ready categories. Some of the virtues of evidentialism arise from the fact that it correctly frames hard questions about knowledge and justification. Evidentialism correctly brings out just what makes the questions hard. This is not a virtue because making trouble conspicuous is a virtue. The trouble is already plainly there. The virtue is that evidentialism characterizes knowledge and justification in ways that make clear why the hard questions are genuinely difficult questions, and not products of confusion or simple oversight. As an additional benefit, evidentialism offers solutions to the problems as well. When there is no ready and complete evidentialist solution, the view does not preclude promising approaches.

Other virtues arise from the fact that an evidentialist perspective applies to a variety of cognitive attitudes and captures a number of useful epistemic distinctions. Competing approaches do not match its combination of ease and breadth of application. Still other virtues of evidentialism are associated with the fact that it fits better than other theories with a variety of pre-theoretic (intuitive, commonsense) judgments as well as with common practices that bear on epistemic evaluations.

\section{A Version of Evidentialism}

\section{A The main theses}

In this section we sketch the central features of the version of evidentialism we prefer. On this view, a person's evidence is restricted to the person's mental states. Evidence in this sense is closely identified with reasons. The evidence one has consists in the reasons one has to go on in forming beliefs. These reasons include current experiential states, such as those involved in perception, introspection, and occurrent memory. In addition, the experiential states that are fruits of a priori reasoning can serve as evidence. The word 'reasons' is sometimes taken to apply only to believed propositions, not to the sorts of states just mentioned. But in our view, believed propositions need evidential support to serve as evidence. Stored memories might also serve as evidence. It is difficult to specify just which stored beliefs do count as evidence a person has at a particular time. Evidentialist theories can differ about such details while remaining in the spirit of the view.

For a sustained defense of evidentialism, see our papers in Evidentialism: Essays in Epistemology (Oxford: Oxford University Press, 2004). 
The justified doxastic attitude toward a proposition is the one that fits the totality of one's evidence. When one's evidence is counterbalanced, suspension of judgment is the justified attitude. When the evidence better supports a proposition than its negation, belief is the justified attitude. Some versions of evidentialism hold that merely having evidence that better supports a proposition over its negation is not sufficient to make belief the justified attitude, and that something more decisive is needed to justify beliefs. ${ }^{2}$ Our view is that any modest overall support is enough to make belief the justified attitude. More support is required to satisfy the justification condition for knowledge. Our view is that the degree of support required to satisfy the justification condition is best captured by the criminal standard: a belief is well-enough justified for knowledge provided that one's evidence supports the belief beyond all reasonable doubt.

Any adequate version of evidentialism will identify two distinct epistemic evaluations. On the one hand, there is the doxastic attitude that is supported by the evidence one has. This is the justified attitude. But a person need not adopt that attitude, and when one does adopt the justified attitude, it might be adopted for the wrong reasons. In our terminology, when one believes a proposition, but not on the basis of proper reasons, one has a belief that is not well-founded.

Finally, it is not an assumption of our version of evidentialism that a person's evidence supports a proposition only if the person justifiably believes that the evidence does support the proposition. It is difficult to state in a precise way the general thesis about beliefs about evidence that we wish to deny. However, an example should make the idea reasonably clear. Suppose that someone familiar with trees sees a typical sugar maple in good light and, on the basis of visual perception, believes that there is a tree there. In the typical case, this will be a well-founded belief. The person need not also believe anything to the effect that having a tree-ish visual experience justifies, or makes probable, that there is a tree present. The person need not have any epistemological beliefs like this at all. Perhaps, however, in the typical case the person has justification for believing such things. Some versions of evidentialism do include the sort of meta-level requirement that we are rejecting. ${ }^{3}$

\section{B The Truth Connection}

As Stewart Cohen has argued, there is some especially close and important connection between epistemic justification and truth. Evidentialism gives a good account of such a connection: The epistemic justification for believing a proposition consists in evidence for its truth. Notably, this same connection exists when the justified belief is false. Epistemic justification for the false proposition that September has 31 days is evidence that it is true that September has 31 days.

\footnotetext{
If there are degrees of belief, then the justified degree of belief is the one that matches the strength of evidential support.

3 For discussion, see Richard Fumerton, Metaepistemology and Skepticism (Lanh;am, Md.: Rowman and Littlefield, 1995).
} 
Some commentators have argued that a defect of the sort of evidentialism that we prefer is that it fails to connect justification to truth in a proper way. As Hilary Kornblith has argued, ${ }^{4}$ the view we endorse allows for the possibility that most of one's justified beliefs are false. This conclusion is supposed to show that evidentialism severs justification from truth. Contrary to Kornblith's remarks, according to evidentialism there is the connection between justification and truth that we noted: when belief in a proposition is justified, it is based on evidence supporting its truth. Nevertheless, our evidentialism does allow that most justified beliefs can be false. This is a virtue of the theory. It captures the strong intuition that victims of massive deception can have mostly justified beliefs no matter what proportion of the beliefs are false. ${ }^{5}$

In our view, it is the non-evidentialist theories that have a hard time making a proper connection between justification and truth. Reliabilism may make the connection Kornblith discusses. Since reliable processes usually lead to truth, reliabilism may imply that most justified beliefs are true. ${ }^{6}$ However, it is not clear that reliabilism does have this implication. Some reliabilists have suggested that the reliability of a process is measured by its propensity to cause true beliefs. ${ }^{7}$ Since it is possible that a process with a propensity to cause true beliefs does not actually lead to mostly true beliefs, reliabilism about justification does not clearly imply that most justified beliefs are true. In any case, reliabilism establishes no interesting connection between a particular belief's justification and its truth. Compare: if a fool wanders into a meeting of MENSA, then his beliefs are in a class with mostly true beliefs. (The class includes all the beliefs in the meeting room. We assume that the beliefs are where the believers are and that most beliefs of MENSA members are true.) In each case, the belief is in a class containing mostly true beliefs. But being in such a class is not connected in any interesting way to truth. The false beliefs just happen to be in good company. Similarly, a belief's being caused by a process that mostly leads to truths is not a connection to the truth of the content of that belief itself.

It is difficult to be confident in claims about what constitutes a genuine truth connection. Demanding that a theory imply that all or most justified beliefs must be true is demanding that the theory imply something false. There is some connection between epistemic justification and truth that is present whether the justified belief is actually true or not. Evidentialism accounts for this. It is not clear that rival theories can do so.

See Roderick Chisholm and the Shaping of American Epistemology, Metaphilosophy 34 (2003): 582602. See especially, pp. 591-2.

5 Whether such believers have knowledge in those cases in which their beliefs are true depends upon details about their situations and upon exactly what the other conditions for knowledge are. For example, it may be that the presence of such massive error constitutes a knowledge defeater for those justified beliefs that happen to be true.

6 Again, we think that this implication would be a liability rather than a strength.

7 See William Alston, Beyond "Justification": Dimensions of Epistemic Evaluation (Ithaca: Cornell University Press, 2005). See especially Chapters 5 and 6. 


\section{Contingency of doxastic responses}

On our view, justification strongly supervenes on a body of evidence. ${ }^{8}$ So, an epistemically justified doxastic response to a body of evidence is essentially (or necessarily) a justified response. Externalists contend that the justified response can be a contingent matter. This raises a delicate issue, as a simple example will bring out.

Assume for the sake of argument that you know that the New York Times is a reliable source of information about a particular topic. You see a report on that topic in the Times and you believe what it says. Our evidentialist theory is designed to allow that this might be a justified response. It is, of course, a contingent fact that the Times is a reliable source. There are other situations in which it would not be appropriate to believe what one reads there. Evidentialism plainly can allow for this possibility. Background evidence, in this example your background evidence about the reliability of the Times, makes the crucial difference. If the "source" of your justification is construed narrowly, to refer to just the report in the Times, then the fittingness of the belief is a contingent matter. If the source is construed more broadly, in a way that includes all the background factors, then the fittingness of the belief is not a contingent matter.

We note that the general evidentialist perspective allows that there are contingent evidential relations which determine epistemic justification. We endorse the strong supervenience thesis, but this claim is not entailed by the fundamental evidentialist thesis that evidence determines justification.

\section{Some questions to be resolved}

A fully worked out version of evidentialism must spell out answers to some admittedly difficult questions. Three such questions arise from the brief account of the theory just given. The first question concerns the nature of the support that perceptual states supply to external world beliefs. One's experience of feeling warm often plays some central role in justifying one's belief that one is in a warm place. Does this experience justify in virtue of its having propositional content, or by some pure phenomenal character that it has? Whichever answer one gives, further difficult questions arise. If the experience has propositional content, exactly what is that content? How does the content relate epistemically to the phenomenal character of the state, on the one hand, and to the justified belief on the other? If instead the experience of feeling warm helps to justify the belief that one is in a warm place in virtue of its qualitative character, how does an internal phenomenal state manage to be a reason for a belief concerning external temperature?

The strong supervenience claim implies that necessarily, if two individuals have the same evidence, then they are justified in believing the same propositions. A weaker evidentialist thesis holds that two individuals in the same possible world who have the same evidence are justified in believing the same propositions. 
These questions do not arise only for evidentialist theories. Any acceptable theory of justification must acknowledge that experiences can make a similar justifying contribution.

A second difficult question for evidentialism concerns the evidential status of stored beliefs and memories. It seems clear that deeply buried memories that could only be retrieved through extensive psychoanalysis do not bear on the epistemic status of one's current beliefs. However, some stored information does seem relevant. Thus, if a person has come to have a method for justified identifications of oak trees by the shape of their leaves, then the person can have a justified belief that there is an oak tree present when the person sees an appropriate shape. It is not necessary that the person consciously entertain a proposition to the effect that the shape is indicative of oaks, nor must the person think of any reasons supporting this proposition. The justification of the oak tree beliefs does depend on using the remembered method, though. The difficult issue is to specify in a general and informative way which memories affect justification and which do not.

Again, this problem is not restricted to evidentialist theories. Any acceptable theory of justification must account for the distinction between those memories that do affect justification and those that do not.

A third difficult question concerns the basing relation. Suppose one's overall evidence supports a proposition, and one believes that proposition. What, exactly, is required for one to believe that proposition on the basis of the proper evidence? The challenge is to explain the distinction between believing the right things for right reasons and believing the right things, but not for any right reason (where right is epistemically understood).

In this case too the challenge exists regardless of one's approach to the nature of justification. No adequate theory can fail to accommodate this difference.

\section{Correctly framing the issues}

In this section we will identify two widely discussed epistemological issues and argue that evidentialist accounts of knowledge and justification make it clear just why these are genuine issues. In each case, the problems can be well understood as questions about the character and quality of one's evidence. In contrast, nonevidentialist theories such as reliabilism fail to make sense of these questions.

\section{A A priori justification and knowledge}

Philosophers have long argued about the existence of a priori knowledge. It seems to some that knowledge outstrips what could be learned entirely from experience. Most centrally and impressively, there are many mathematical and logical propositions that people know without having any apparent justification from an empirical source. The justification seems not to arise from sensory experience, memory, or introspection. These examples give strong reason to think that there is a priori knowledge and justification. 
Yet a priori knowledge is a strange thing. It seems dubious that people can know anything about the world independently of experience. For instance, someone thinks hard about some mathematical matter, with no apparent use of empirical information, and a belief emerges that seems outstandingly well justified. Great minds agree that the thinking proves the belief to be true. This is a remarkable phenomenon. Conceiving of an abstract proof uncomfortably resembles making up a coherent fairy tale. How does the proving generate knowledge? A central puzzle here is that of how the thinking involved gives a resulting belief epistemic justification.

This problem is readily understood as a question about evidence. As the mathematical thinking proceeds, what exactly is the evidence that it brings forth? The answer to this question is not at all obvious, though there are plausible indications that evidence is indeed acquired. The thinking does seem to develop an answer to the question: what reason is there to think that the proposition is true? The reasons that emerge from the thinking qualify as evidence for the mathematical proposition.

In a way, the case of a mathematical proof is not the most puzzling case. The premises of the proof can be cited as justifying evidence for the propositions that are inferred from them. So there is some readily cited evidence for any proven conclusion. But the fundamental puzzle remains. In the case of proofs, the difficulty consists in seeing why the premises qualify for use to gain justification. What justifies the ultimate premises? This same difficulty is present in a starker way in cases in which an abstract proposition seems to be known with no need for proof. People are inclined to say that the proposition is just obvious, or that the proposition is self-evident. The fundamental epistemological problem is to identify the justification that makes for obviousness or self-evidence.

The problem is well understood to be a question about evidence. The challenge is to explain the source or basis of obviousness, or self-evidence, so that it clearly constitutes evidence of truth. Robert Audi's helpful account of selfevidence has it that a proposition is self-evident when an adequate understanding of the proposition is sufficient for knowledge of the proposition. ${ }^{9}$ In terms of this account of self-evidence, the pressing question is this: what justification does an adequate understanding deliver that enables one to know the proposition? This question is sharpened by focusing on evidence. The question becomes: how does merely understanding what a proposition asserts provide strong evidence that the proposition is true, and what is that evidence?

Suppose instead that justification derives from the operation of a reliable mechanism or relevant belief-forming process type. Reliabilists might say that a belief is justified a priori when it results from a belief-forming process that is of a reliable type and that does not use empirical inputs. ${ }^{10}$ Suppose that our logical and

See Robert Audi, Epistemology: A Contemporary Introduction to the Theory of Knowledge (New York: Routledge, 1998), p. 95.

10 This is approximately the account defended by Louise Antony in "A Naturalized Approach to the A Priori," Philosophical Issues 14 (2004): 1-17. 
mathematical thinking does in fact usually lead to true beliefs and that the process (or processes) involved are of the type abstract thinking. Suppose, finally, that abstract thinking is a reliable process type. By declaring abstract thinking to be the relevant type of process to determine reliability in these cases, we can conclude that the beliefs have reliabilist justification. And if the abstract thinking does not make use of empirical inputs, we can say that this justification is a priori.

Although the account just given provides a reliabilist explanation of why the logical and mathematical beliefs are justified, the puzzle remains. What is it in that thinking that gives us good reasons to believe the resulting propositions? This question is well understood as a question about how the thinking manages to provide good evidence. Reliabilists might argue that there really is no mystery here, or perhaps that the only mystery is an empirical one about why a reliable abstract thinking process would evolve in us. The key fact for epistemology, they might say, is that our minds simply function in such a way that they are able to arrive at true beliefs about mathematics without explicitly relying on empirical inputs. In such cases, we have a priori knowledge. But surely this overlooks a key aspect of the phenomenon. It is not just that we arrive at true beliefs about mathematical matters. The remarkable thing is that, just by thinking, we somehow acquire extremely good reasons to accept some mathematical propositions. What is puzzling is just what kinds of reasons we are capable of acquiring just by thinking. Reliabilism is simply silent on this puzzle. ${ }^{11}$

Consider now the idea that justified beliefs are epistemically responsible beliefs. Thus, a belief would be justified a priori because it was believed in an epistemically responsible manner without relying on empirical information. This theory overlooks the puzzle. Essentially the same epistemological questions remain: Why are some propositions believed responsibly, when they are believed after just reflecting on what they say? What sort of reason does that thinking produce? The basis for responsible believing remains to be accounted for.

Similarly inadequate are the ideas that justified beliefs are the results of proper function, or the exercise of epistemic virtue. Perhaps people believe the simplest tautologies in a way that conforms to their cognitive design and exercises epistemic virtue. But what is it about one's coming to believe a simple tautology that makes it proper and virtuous to believe it? If people believe such things on the basis of good enough reason, then these questions seem to be adequately answered, and not otherwise. It is part of an evidentialist view that people do have good enough reason when they have justifying evidence. By applying this view here, the basic question about a priori justification comes into sharp focus.

11 It is open to reliabilists to acknowledge that this question about reasons or evidence arises. They need not say that reliability is the only epistemologically significant property. Thus, they can say that justification is a matter of reliability, but there are good questions about reasons and evidence anyway. While such a position is coherent, it is hard to see what reason there is to accept it. What made a priori justification puzzling in the first place was a question about evidence. Why construct a theory about justification that makes the puzzle not a question about justification? 


\section{B External world skepticism}

We turn now to a second difficult issue that we believe to be particularly well framed in evidentialist terms.

Facts about the possibility of error lead some to doubt that any beliefs about the external world amount to knowledge. Evidentialism helps make clear why these skeptical doubts sensibly arise. Suppose that justification depends on evidence and that strong justification is a necessary condition for knowledge. This makes it clear that the possibility of error can plausibly be taken to raise a question about exactly how well justified our beliefs actually are. The possibility of error establishes that there is a kind of weakness, or inconclusiveness, in our evidence. The evidence does not entail the truth of the belief. One can easily see why those worried by skepticism might think that this weakness shows that we lack the justification needed for knowledge. They think that having inconclusive information about the truth of a proposition is incompatible with knowing the proposition.

The skeptical worries raise at least two related questions: how well justified must our beliefs be in order to qualify as knowledge (when the other conditions for knowledge are met); and how well justified are ordinary external world beliefs? Both questions are easily understood, though not so easily answered, in evidentialist terms. Our answer to the first question, as noted earlier, is that the relevant standard is similar to the standard for conviction of the accused in criminal trials in the U.S. One must have evidence that places the proposition beyond reasonable doubt. To characterize the standard in this way is not to spell it out in full detail. It must be explained how evidence allowing the possibility of error nonetheless can place a proposition beyond reasonable doubt. Our account, in a few words, is that when a proposition is strongly supported by one's evidence, reasonable doubt requires having evidence that a contrary possibility does in fact obtain. Concerning ordinary external world beliefs, people often have no evidence for the truth of any contrary possibility. Many typical perceptual and memorial beliefs are beyond reasonable doubt, and can thus be instances of knowledge on this account.

Notably, many theoretical beliefs in science do not meet this standard. But here the evidentialist view seems to get things exactly right. Complex scientific theories are often overthrown. There is often some experimental evidence supporting their falsity. These facts make many theoretical beliefs subject to reasonable doubt. Thus, even when they are well justified, they fall short of knowledge.

A related advantage for the version of evidentialism that we defend involves its strong supervenience thesis. This says in part that evidence for a proposition is necessarily evidence for that proposition. That thesis bears out the relevance of skeptical scenarios. The possibilities of dreaming, and deception by demons and envatters, are by hypothesis possibilities where experiences and apparent memories are the same as in some portions of normal waking life. Why does this threaten our knowledge in normal waking life? Suppose that one's experiences and apparent memories either are themselves all of one's basic evidence or at 
least they settle the question of what evidence one has. By the strong supervenience thesis, then, those in the skeptical scenarios have the same evidence as their normal world counterparts. By evidentialism about justification, this evidence justifies them in believing the same things. The fact that those in the skeptical scenarios are so routinely wrong in their beliefs leads some to doubt that their beliefs are justified. Since people's actual justification is no better than theirs, there is a similar doubt about whether actual beliefs are justified. So the skeptical scenarios clearly pose a skeptical challenge. ${ }^{12}$

Rival theories of justification make it hard to see why skepticism is a challenging question. For example, reliabilist accounts do not typically require perfect reliability for justification or knowledge. So, the mere possibility of error does not call into question that our beliefs have sufficient reliability. The massive falsehood of the beliefs of those in skeptical scenarios makes their beliefs seem conspicuously lacking in the reliability that produces justification, according to reliabilism. However, the skeptical scenarios have no bearing on the reliability of actual belief-forming processes. Why, then, do they seem threatening to actual knowledge? Reliabilism does not explain the allure of skepticism, an allure that it surely has.

It is sometimes seen as a virtue of rival theories that they provide a good basis for rejecting skepticism. This alleged virtue seems to amount to the idea that it would be good if we did have knowledge, and so a theory about knowledge that unquestionably implies that we do have knowledge (when coupled with some assumptions about our place in the world) is therefore a good theory. But surely this is a mistake. Obviously unsatisfactory theories, such as the theory that knowledge is mere true belief, also have this implication. A good theory of knowledge will reveal knowledge to be the sort of thing whose existence is at least sensibly thought to be called into question by the possibility (or actuality) of errors. Evidentialism does this.

\section{The Breadth of Evidentialism}

\section{A Defeat}

A comprehensive theory of epistemic justification must explain and accommodate internal defeaters. Internal defeat occurs when someone has justification for a proposition and, while not losing the basis of that justification, the person becomes less well justified in believing the proposition. ${ }^{13}$

12 The versions of evidentialism according to which the actual evidence for $\mathrm{P}$ is only contingently evidence for P provide no straightforward way to explain the attraction of this skeptical challenge. The fact that the evidence might not have been evidence for $\mathrm{P}$ does not raise a question about how well that evidence actually supports P. It is therefore unclear why the skeptical scenarios even raise a question about actual knowledge.

External defeaters are truths that, according to defeasibility theories of knowledge, leave beliefs epistemically justified while preventing them from being cases of knowledge. 
It is relatively easy to give a plausible account of internal defeat in evidentialist terms. As John Pollock has emphasized, there are two basic types of internal defeaters, rebutting defeaters and undermining defeaters. ${ }^{14}$ Corresponding to the two types of defeaters, evidence for a proposition is defeated by two types of evidence. The first type, a rebutting defeater, is simply evidence against the proposition, that is, evidence for its denial.

The second type of defeating evidence, undermining evidence, is not quite as simple to specify. The classic example involves seeing a red-looking cup on a table. The seeing is some justification for the belief that the cup is red, until one learns that a red light is shining on the cup. If one has typical background information about the effect of red light on white objects and the existence of white cups, then one is no longer well justified in believing that the cup is red when one learns about the red light. On an evidentialist view, one has new evidence and this serves to diminish the strength of one's justification for the proposition that the cup is red. This much seems clear. The problem is to say exactly what the new evidence supports, and how that is related to the initial evidence.

An account along the following lines is plausible. Generally, undermining defeaters are evidence that gives reason to doubt the existence of some otherwise justifying connection between the undermined evidence and the truth of the proposition. Thus, evidence $\mathrm{E}$ for proposition $\mathrm{X}$ is subject to undermining evidence when the person acquires support for some proposition roughly to the effect that this instance of E leaves more room than usual for the falsehood of X. In the red light case, for instance, consider what happens when one who knows the influence of red light on the look of white things learns that a red light is illuminating the red-looking cup. The person thereby gets evidence for some proposition to the effect that white things look red under the prevailing lighting conditions. At that point, the red look, together with this new evidence, supports more weakly, if at all, the proposition that the cup is red.

Other approaches to justification do less well here. For instance, the defeating information might be claimed to make continued belief less reliable. But any claimed difference in reliability seems to be at best contingent. Learning about the red light intuitively undercuts justification even if the fact happens to be that red lights are seen to shine only on red things. ${ }^{15}$

14 See John Pollock, Contemporary Theories of Knowledge (Totawa, NJ: Rowman \& Littlefield, 1986), pp. 36-39.

15 In "What is Justified Belief?" George S. Pappas, ed. Justification and Knowledge (Dordrceht: D. Reidel, 1979) p. 20, Alvin Goldman proposes that the justification of a belief is defeated when one has available a reliable belief-forming process that would lead to not having that belief. Making sense of this requires making sense of the reliability of a process that does not lead to belief. The prospects for this do not seem bright. (See the discussion of suspension of belief, in Section B, below.) 


\section{B Assessing Other Doxastic Attitudes}

It is not just belief that can be readily evaluated by evidentialist standards. Disbelief and suspension of judgment are as readily evaluated. The justification of each attitude emerges in a unified and natural way from the support that the evidence provides: sufficient support for a proposition justifies belief, sufficient support for its negation justifies disbelief, and the absence of sufficient support for either the proposition or its negation justifies suspension of judgment.

It is far harder to see how some rival theories will explain what justifies suspension of judgment. Returning once again to reliabilism to illustrate, it is difficult to make sense of a reliable suspension of judgment process. Suppose that a process leads you to suspend judgment about a proposition, and suppose that the relevant type for this process is a type that only leads to suspension of judgment. We could say that this is a reliable suspension of judgment process if in the relevant set of cases half the propositions it leads to suspension about are true and half are false. This proposal has highly implausible implications. Suppose that you toss a fair coin, see which side is facing up, and suspend judgment about whether the coin came up heads. The proposition will be true about half the time, and so this is a reliable suspension of judgment process according to the proposal just described. Yet suspension of judgment is not justified under the circumstances, since you have good visual information about the truth-value of the proposition. So the relevant set of cases is not the set of fair coin tossings. But what it is, and why is that the relevant set? It is not possible to prove that there is nothing good for reliabilists to say about justified suspension of judgment, but it is clear that the theory is not well-suited to account for it.

Other doxastic attitudes, such as doubt and suspicion, can be justified in a way that is broadly epistemic. Evidentialism provides for natural proposals about this. Having some doubt about the truth of a proposition is justified by having evidence against it. Alternatively, an evidentialist can hold that having a doubt is justified by something weaker, such as lack of evidence in its favor. Suspecting that something is true is likewise amenable to evidentialist analysis. Criminal investigations offer a helpful analogy. A suspect in a crime is a person against whom investigators have some evidence, without having strong excluding evidence. The person remains a mere suspect if approximately equally substantial counter-evidence exists, such as the existence of similar evidence that points to some other culprit instead. Similarly, having some evidence in favor of a proposition, and no conclusive evidence against the proposition, justifies suspecting that it is true, when one has about equally substantial counter-evidence.

In contrast, it is difficult to see any natural reliabilist explanation of the justification of such attitudes. They seem to lack any close connection to truthconducive mechanisms or processes. Explanations in terms of responsibility, virtue, or proper function seem incomplete in a familiar way. Ending the explanations with reference to these features leaves it unclear why they are present in the cases where the attitudes are justified. We suggest that either the explanati- 
on of, say, responsible belief, is, finally, that it is belief based on good evidence or the account gets some cases wrong. In the former case, the view is a roundabout version of evidentialism. In the latter case, the view is mistaken.

Emotive attitudes are also capable of justification. One can be justifiably angry about an insult or feel justifiably guilty about a misdeed. These emotive attitudes seem to involve beliefs. Anger about an insult includes beliefs to the effect that a certain something said was about one, and that such a saying is insulting. A feeling of guilt about a misdeed involves beliefs to the effect that the deed was done and that it was wrong. When the emotive attitudes are justified, this requires that the involved beliefs are justified. ${ }^{16}$ Evidentialism requires evidence for the involved beliefs, if they and the emotions involving them are to be justified. This works out well as a test for justified emotions. The most clearly unjustified emotions involve beliefs for which the person has inadequate evidence. Some emotions are less clearly connected with beliefs. For example, an unreasonable fear that there will be a blizzard does not require believing that there will be a blizzard. It is unclear what belief, if any, it does require. The fear may result from the thought that there is a small likelihood of a blizzard. Yet sense can be made of the idea that such a fear is unjustified: one is lacking evidence that there will be a blizzard. Thus, the justification of even these emotions makes clear sense in evidentialist terms.

\section{Making Sense of Philosophy}

Philosophers defend philosophical theses. Given the history of problems and refutations of philosophical views, it is not plausible that we can often gain knowledge of philosophical truths. In light of this, what epistemic good is reasonably thought to be done by philosophical work in defense of a philosophical theory?

Evidentialism offers an attractive answer to this question. Philosophers defend theories by in effect seeking to present evidence for their theories or evidence against objections to their theories. By finding such evidence, they advance the justification of their views. This is a reasonable activity to engage in, whether or not knowledge of philosophical theories is a tainable. Once again, reliabilism seems less well suited to answer the question. Except to the extent that the defense of philosophical theories involves the pursuit of evidence, which may be a reliable basis for belief, there is nothing discernably reliable about apparently good philosophical methods.

16 This justification is not sufficient, however, because the emotion is justified only if it is also a fitting response to the involved beliefs. 


\section{Conclusion}

Evidentialism has many virtues beyond the ones cited here, perhaps thousands of them. There is no need to try to list them all, but the virtues of evidentialism do need a bit of extolling. There are some tough problems involved in completing the theory, including the problems described above of giving complete accounts of perceptual and memorial evidence. Nevertheless, the virtues of evidentialism provide encouragement enough to continue seeking solutions to the remaining problems until they are found. ${ }^{17}$

${ }^{17}$ An earlier version of this paper was presented at the 2005 Central Division Meeting of the American Philosophical Association. We are grateful to the commentator, Michael Bergmann, for his helpful comments, and to the members of the audience for their questions. 